\title{
Association of Interleukin-27 rs 153109 Single Nucleotide Polymorphism with Spontaneous Resolution of Hepatitis C Virus - Genotype 4a Infection in Egyptian Patients
}

\author{
Mariam M Fawzy $^{1 \&}$, Ahmed Wahid ${ }^{1 \& *}$, Maiiada H Nazmy' ${ }^{1}$, Mohamed Hashem², \\ Imam Waked ${ }^{3}$, Sayed F Abdelwahab ${ }^{4,5}$
}

\begin{abstract}
Background: HCV is a major global health problem. IL-27 is a member of the IL-6/IL-12 cytokine family with a broad range of anti-inflammatory properties. Recent studies highlighted the effect of a SNP in the IL-27 promoter region on modulating the progression of infectious diseases and individual responses to therapy. Aim of the work: The present study investigated the potential role of $(-964 \mathrm{~A} / \mathrm{G}) \mathrm{SNP}$ in the promoter region of IL-27p28 gene (alleles rs153109) on the outcome of HCV infection among genotype 4a infected patients. Materials and Methods: HCV genotyping confirmed that all of the HCV-infected patients had genotype 4a infection. Genomic DNA was extracted from 111 patients with chronic HCV infection, 42 spontaneous resolvers (SR) and 16 healthy controls. IL- 27p28.rs153109 genotyping was assessed using PCR-RFLP then confirmed by DNA sequencing. Results: The frequency of IL-27-p28.rs153109AA, AG, and GG genotypes among chronically infected subjects were $74.8 \%, 25.2 \%$, and $0 \%$ while among the SR, they were $57.1 \%, 35.7 \%$, and $7.14 \%$, respectively. Our data show the unique presence of G/G genotype in the SR group (3 patients; $7.14 \%)$. Moreover, the "G" allele frequencies among chronic and resolved subjects were $12.6 \%$ and $25.0 \%$, respectively $(p=0.0136)$. Importantly, subjects with the GG genotype were more likely to clear their HCV infection than those with the AA genotype (p=0.0118). Conclusions: HCV genotype 4a subjects with the IL-27-p28.rs153109 A/G and G/G genotype were more likely to clear their HCV infection. Therefore, we propose IL- 27p28.rs153109SNPas a genetic biomarker for predicting HCV infection outcome.
\end{abstract}

Keywords: HCV infection - genotype 4 - interleukin 27 p-28 (-964 A/G) - spontaneous resolvers - Egypt

Asian Pac J Cancer Prev, 17 (4), 2093-2097

\section{Introduction}

Hepatitis $\mathrm{C}$ virus (HCV) is an RNA virus.It is a major global health problem as it infects $\sim 3 \%$ of the world's population (Parkin 2001; Baldo et al., 2008). Indeed, around 170 million individuals of the world's population are infected with $\mathrm{HCV}$. According to the WHO estimation, the highest prevalence of HCV infection is found in Egypt; where $\sim 15 \%$ of the adult Egyptian populations are infected (Peralta et al., 2012). HCV patients are at high risk of developing liver cirrhosis, and eventually hepatocellular carcinoma (Chen and Morgan 2006; Wahid and Dubuisson 2013).

Unfortunately, the outcome mechanisms of $\mathrm{HCV}$ infection remain; so far; unclear. The coordination between innate and adaptive immunity is strongly required for a successful clearance of HCV infection. There is no doubt that cytokines including IL-27 play a great role as a link between both adaptive and innate immunity (Koziel 2005). IL-27 is a type 1 cytokine, and is a member of IL-6/IL-12 family. It has a pivotal effect on T-cells and acts on innate immune cells (Pflanz et al., 2002).IL-27 is comprised of two subunits, IL-27 p28 and EBI3 (Sprecher, Grant et al., 1998; Morishima, Mizoguchi et al., 2010).IL27 binds to receptor complex composed of IL-27R $\alpha$ (also called WSX-1) and gp 130 (Pflanz et al., 2004; Kastelein et al., 2007). Upon binding to its receptor in naïve CD4+ $\mathrm{T}$ cells, IL-27 activates JAK/STAT signaling inducing transcription of effector genes (Ihle, 2001; Takeda et al., 2003; Sonobe et al., 2005). IL-27 was reported previously

${ }^{1}$ Department of Biochemistry, Faculty of Pharmacy, ${ }^{4}$ Department of Microbiology and Immunology, Faculty of Medicine, Minia University, Minia, ${ }^{3}$ Hepatology Department, National Liver Institute, Menoufiya University, Menoufiya, Egypt, ${ }^{2}$ Department of Epidemiology and Public Health, University of Maryland School of Medicine, Baltimore, Maryland, USA, ${ }^{5}$ Microbiology Department, Faculty of Pharmacy, Taif University, Taif, Kingdom of Saudi Arabia ${ }^{\circledR}$ Equal contributors *For correspondence: ahmed_wahid@ mu.edu.eg 
to exert both pro-inflammatory and anti-inflammatory effects and have a role in acute phase response to infections (Ihle 2001; Pflanz et al., 2002; Takeda et al., 2003; Sonobe et al., 2005).

It has been reported before that IL-12 family members were shown to play a crucial role against viral infections(Hunter 2005; Ryan and O'Farrelly 2011). Similarly, a previous study demonstrated that IL-27 has INF-like response as it induces antiviral genes including PKR, 2'-5' Oligoadenylate synthase and myxovirus protein 1 (Frank et al., 2010).Indeed, IL-27 was shown to be a potent inducer of IFN-gamma, which inhibits the viral replication (Tang et al., 2003). IL-27 was shown recently to inhibit human influenza virus, HIV, and HCV replication by inducing an IFN-like response (Fakruddin et al., 2007; Imamichi et al., 2008; Frank et al., 2010; Liu et al., 2012).The effect of SNP of IL27p28 (especially c.-964A/G (rs153109) on progression of various diseases such asassociation between HBV and HCC (Peng et al., 2013), HBV susceptibility(Yasser et al., 2014) and response to HCV genotype 1 therapy (Zicca et al., 2014) has been evaluated. Here we examined the effect of IL27-p28.rs153109 SNP on the ability of patients infected with HCV genotype 4 a to spontaneously resolve their infection.

\section{Materials and Methods}

\section{Patients}

One hundred and sixty nine Egyptians were enrolled in this study. They were classified into three groups. The first group included 111 patients with chronic HCV (80 males and 31 females) with age range from 20 to 62 years. The second group included 42 spontaneous resolvers ( 30 males and 12 females) with an age range from 23 to 84 years (the same ratio between chronic and spontaneous resolvers was shown in previous reports (Knapp et al., 2011; Sharafi et al., 2014; Abdelwahab et al., 2015). Obviously this is because of the difficulty of collecting a large number of samples of spontaneous resolvers). The third group included 16 healthy controls with an age range from 21 to 50 years, with no history of previous liver disease (HBV and HCV infection are negative). Patients and controls enrolled in the current study were matched for age, ethnicity and geographical residence.Patients with HBV or other viral infections or any other liver diseases were excluded.

HCV chronically infected patients and spontaneous resolvers were recruited from the National Liver Institute, Menofiya University, Egypt. All subjects were treatment naïve at the time of enrollment and consequently HCV-RNA negative and antibody positive subjects were considered spontaneous clearers of the infection. Spontaneous viral clearance was defined as being HCV RNA-negative and anti-hepatitis $\mathrm{C}$ antibody-positive without receiving hepatitis $C$ treatment in two consecutive tests with an interest interval $\geq 6$ months(Haibo Sun and Bing Sun 2015). Patients enrolled in this study were subjected to the following procedures: full history taking, assessment of liver function (i.e. liver transaminases (ALT and AST) activities, total bilirubin and albumin).
Genotyping of HCV was conducted as previously described (Ohno et al., 1997).

The current study was conducted in accordance with the Code of the World Medical Association (Declaration of Helsinki) for experiments involving humans. The study protocol was approved by Faculty of Pharmacy, Minia University research ethics committee. A written informed consent to enroll in the present study was obtained from all patients and controls enrolled in the study.

\section{DNA isolation and determination of the DNA quality and concentration}

Genomic DNA was extracted from whole neutrophil samples by QIAamp DNA Blood Mini Kit (Qiagen, Germany) according to the manufacturer's instructions. Extracted DNA was applied to $1 \%$ agarose gel to confirm the presence of genomic DNA. The concentration of DNA in all samples was measured using a Nanodrop 2000 (Thermo Scientific, United States). DNA quality was assessed by calculating the Kalckar's formula (the OD260/OD280 ratio) in order to determine an estimate for the purity of the nucleic acid.

\section{IL-27p28.rs153109 genotyping}

IL-27p28 (-964 A/G) (rs153109) SNP was determined by PCR-RFLP. The PCR primers were constructed as reported (Yasser et al., 2014). The sequence of the forward primer was as follows: 5 '-GGCTGTGCTGGAAGGGAGAC-3' while that of the reverse primerwas: $5^{\prime}$-ATATCTGGGACCAGGGTTAGG$3^{\prime}$. The PCR reaction was performed as reported(Yasser, Samir et al., 2014) with some modifications.

Briefly, a 12.5 $\mu$ l of Taq PCR Master Mix (Qiagen.), $10 \mathrm{pmol} / \mathrm{l}$ of each primer (Invitrogen) and 150ng DNA were mixed. The PCR cycling was performed as follows: 1 cycle of $94^{\circ} \mathrm{C}$ ( 5 minutes), followed by 35 cycles of $94^{\circ} \mathrm{C}$ ( 1 minute), $59^{\circ} \mathrm{C}$ for $45 \mathrm{~s}, 72^{\circ} \mathrm{C}$ for 2 minutes and a final extension step at $72^{\circ} \mathrm{C}$ for $10 \mathrm{~min}$. PCR reaction was performed by Veriti ${ }^{\circledR} 96$ well thermal cycler (Applied Biosystems, USA). The 468 bp PCR product was visualized on a $2 \%$ agarose gel. PCR product $(10 \mu \mathrm{l})$ was subjected to digestion with XhoI restriction enzyme (Invitrogen, USA).This digestion yielded DNA fragments of $468 \mathrm{bp}$ (A/A genotype), 468/347/121 bp (A/G genotype) and $347 / 121$ bp (G/G genotype) using 100 bp DNA ladder (Qiagen, Gemany). All genotypes were confirmed by sequencing using 3500 Genetic Analyzer (Applied Biosystems, USA).We could detect SNP rs153109 by sequence analysis based on the reference Homo sapiens sequence of chromosome 16 genomic contig GRCh37. p13 Primary Assembly (NCBI Reference Sequence: NT_010393.16).

\section{Statistical analysis}

The software GraphPad Prism 5 (GraphPad,Inc, La Jolla, CA) was used to calculate two-tailed $p$ values between $\mathrm{A} / \mathrm{A}$ and $\mathrm{A} / \mathrm{G}$ genotypes in both chronic and spontaneous resolvers from $2 \times 2$ contingency tables using Fisher exact test and to calculate $\mathrm{p}$ values between $\mathrm{A} / \mathrm{A}$, $\mathrm{A} / \mathrm{G}$ and $\mathrm{G} / \mathrm{G}$ genotypes in the groups using Chi square test. 


\section{Results}

Clinical characteristics of the study population

Patients with chronic hepatitis $\mathrm{C}$ were positive for HCV antibody (Ab) and HCV-RNA, whereas spontaneous resolvers were positive for $\mathrm{HCV}$ antibody, and negative for HCV-RNA. Controls were negative for $\mathrm{HCV} \mathrm{Ab}$ and HCV-RNA. The biochemical profile of patients enrolled in the current study is shown in Table 1.There were significant increase in ALT and AST activities and total
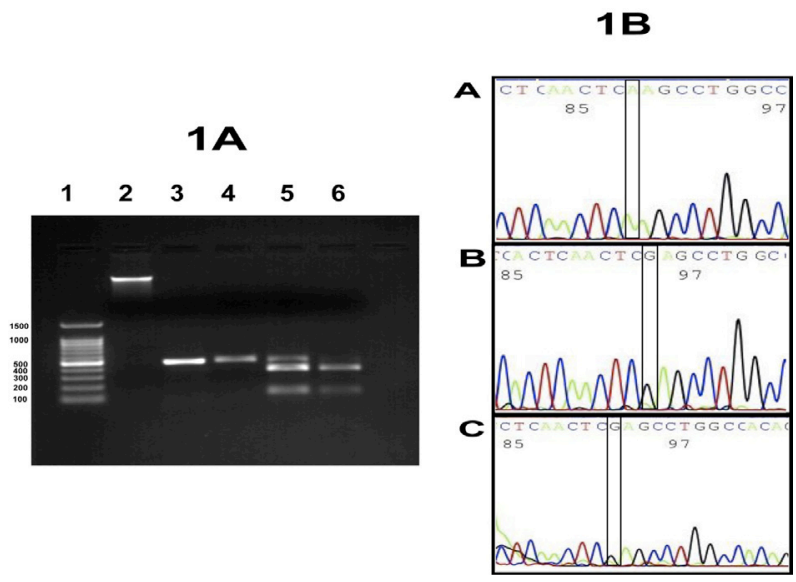

Figure 1. A) PCR products for different groups. Lane 1: shows GelPilot 100 bp Plus Ladder (100) DNA ladder. Lane 2: genomic DNA, lane 3: PCR product before digestion. Lanes 4, 5 and 6: are the digest of $\mathrm{A} / \mathrm{A}, \mathrm{A} / \mathrm{G}$ and $\mathrm{G} / \mathrm{G}$ genotypes respectively.G/G genotype is homozygous having $\mathrm{G}$ allele in the 2 copies of the chromosome so the enzyme cuts in both giving 4 pieces (each 2 have the same length so appear as 2 bands $347 \mathrm{bp}$, $120 \mathrm{bp}$ ) while $\mathrm{A} / \mathrm{G}$ is heterozygous only one chromosome has the $\mathrm{G}$ allele so the enzyme leaves one uncut $480 \mathrm{bp}$ and cut the other into 2 pieces $(340,120)$ so $\mathrm{A} / \mathrm{G}$ genotype appears as 3 bands. B) $\mathrm{A}, \mathrm{B}$ and $\mathrm{C}$ show the sequencing results for the forward strand of $\mathrm{A} / \mathrm{A}, \mathrm{A} / \mathrm{G}$ and $\mathrm{A} / \mathrm{G}$ genotypes respectively bilirubin levels among all three groups $(\mathrm{p}<0.05)$. But non-significant changes were observed in direct bilirubin and albumin levels ( $p>0.05)$ among various groups.

Association of IL-27p28 (-964 A/G) gene polymorphisms with the outcome of HCV infection

The rs153109 alleles of the IL-27p28 gene were examined among patients with chronic hepatitis $\mathrm{C}$ (genotype 4a) and spontaneous resolvers. We analyzed the genotype ofIL-27-p28.rs153109 on -964A>G using PCR and RFLP. The restriction analysis product of each PCR sample was visualized on $2 \%$ agarose gel and classified according to the position of DNA fragments into AA, AG and GG genotypes (Figure 1).

Our data revealed a differential distribution of IL27p28.rs153109 genotypes among Egyptian patients.AG genotype was found in 28 out of 111 (25.2\%) chronic HCV patients, 15 out of 42 of SR $(35.7 \%)$ and 10 out 16 controls (Table 2). The "A" allele frequencies among the chronic and resolved subjects were $87.4 \%$ and $75 \%$, respectively. On the other hand, the " $G$ "allele frequencies among

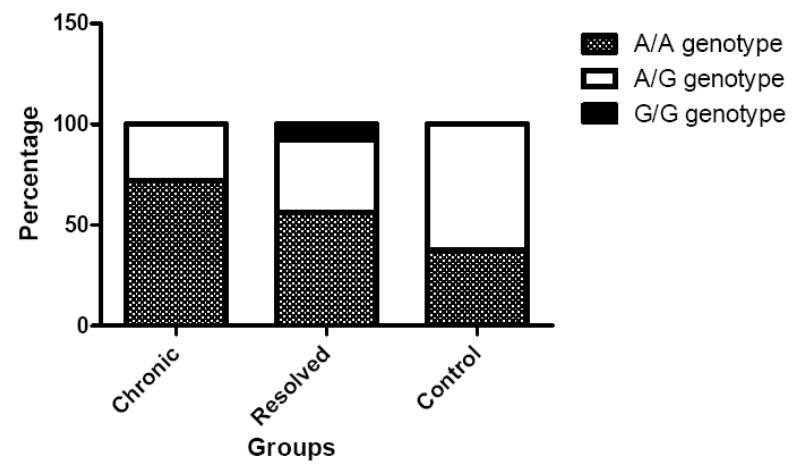

Figure 2. Genotype Frequencies of IL-27p28 (-964 A/G) in Different Groups

Table 1. Biochemical Profile for Different Groups

\begin{tabular}{|c|c|c|c|c|}
\hline \multirow{2}{*}{ Characteristics } & Chronic $\mathrm{HCV} \pm \mathrm{SD}$ & $\mathrm{SR} \pm \mathrm{SD}$ & Control $\pm \mathrm{SD}$ & \multirow{2}{*}{ P-value } \\
\hline & $\mathrm{N}=111$ & $\mathrm{~N}=42$ & $\mathrm{~N}=16$ & \\
\hline ALT & $48.0 \pm 3.3$ & $36.5 \pm 5.3$ & $18.7 \pm 5.1$ & $0.0026 * *$ \\
\hline AST & $67.4 \pm 4.4$ & $46.4 \pm 5.7$ & $21.2 \pm 5.9$ & $<0.0001 * * *$ \\
\hline Bilirubin & $1.2 \pm 0.1$ & $0.8 \pm 0.1$ & $0.66 \pm 0.18$ & $0.015 *$ \\
\hline Direct bilirubin & \pm 0.10 .6 & $0.4 \pm 0.1$ & $0.10 \pm 0.12$ & 0.095 \\
\hline Albumin & $4.4 \pm 0.1$ & $4.8 \pm 0.1$ & $4.3 \pm 0.39$ & 0.07 \\
\hline
\end{tabular}

*Data are expressed as X- \pm SD. Significant difference between groups was analyzed by one-way ANOVA, where: (P<0.05 is considered significant).

Table 2. Genotype Frequencies of IL-27p28 (-964 A/G) in Different Groups

\begin{tabular}{ccccc}
\hline \multirow{2}{*}{ Genotypes } & Chronic HCV & SR & Control & \multirow{2}{*}{ p value } \\
\cline { 2 - 4 } & $\mathrm{n}(\%)$ & $\mathrm{n}(\%)$ & $\mathrm{n}(\%)$ & $37.50 \%$ \\
\multirow{2}{*}{$\mathrm{AA}$} & $74.80 \%$ & $57.14 \%$ & $(6 / 16)$ & \\
& $(83 / 111)$ & $(24 / 42)$ & $62.50 \%$ & $0.0118^{*}$ \\
\multirow{2}{*}{$\mathrm{AG}$} & $25.20 \%$ & $35.70 \%$ & $(10 / 16)$ & $0 \%$ \\
& $(28 / 111)$ & $(15 / 42)$ & $(0 / 16)$ & \\
\hline \multirow{2}{*}{ GG } & $0 \%$ & $(3 / 42)$ & & \\
\end{tabular}

*Comparing resolvers and chronic HCV subjects by chi square test. 
Table 3. Allele Frequencies Diffrence Between Chronic HCV Subjects and Spontaneous Reolvers

\begin{tabular}{cccc}
\hline & Chronic & Spontaneous resolvers & p value \\
\hline A allele & $87.40 \%$ & $75 \%$ & $0.01368 *$ \\
G allele & $12.60 \%$ & $25 \%$ & \\
\hline
\end{tabular}

*Comparing resolvers and chronic HCV subjects by chi square test

the chronic and resolved subjects were $12.6 \%$ and $25 \%$, respectively ( $\mathrm{p}=0.0136$ )(Table 3).The IL27p28.rs 153109 GG genotype was present only in 3 SR subjects $(7.14 \%)$ with complete absence in the chronic $\mathrm{HCV}$ patients. The distribution of GG genotype and other genotypes (AA and $A G)$ was significantly different among the study populations ( $\mathrm{p}=0.0196)$. Importantly, subjects with the GG genotype were more likely to clear their HCV infection than those with the AA genotype $(\mathrm{p}=0.0118)$.

\section{Discussion}

The aim of the present study is to investigate the association between IL-27p28 (-964 A/G) SNP and HCV outcome among Egyptian HCV patients with genotype 4a infection. We showed that subjects with the GG genotype were more likely to clear $\mathrm{HCV}$ infection than those with the AA genotype. IL-27 is a pleiotropic anti-inflammatory cytokine. It has been shown that IL-27 plays a crucial role in Th1-mediated responses. These responses may lead to excessive cell-mediated immunity (Batten and Ghilardi 2007). Therefore, overproduction of IL-27 is expected to have an impact on chronic hepatitis $\mathrm{C}$ evolution. Efforts are exerted to study the effects of host and viral factors on different diseases progression and treatment outcome. For example, host factors like SNPs in IL-28B were found to affect virus evolution of hepatitis $\mathrm{C}$ quasispecies following to treatment by pegylated interferon and ribavirin (Komatsu et al., 2014).IL-27 was first described in 2002 as a novel member of the IL-6/IL-12 family (Pflanz, Timans et al., 2002) and is known as an essential linker between innate and adaptive immunity. It plays an important role in B and T-lymphocytes regulation. It acts together with IL-12 to potentiate interferon gamma production (Sprecher et al., 1998).

IL-27 was reported previously as a next generation biomarker predicting the outcome of several human diseases and their complications. For example, the association between IL-27p28 (-964 A/G) (rs153109) SNP and susceptibility to asthma and inflammatory bowel disease was found in Korean population (Chae et al., 2007; Li, Zhang et al., 2009). Also, it was suggested that IL-27p28 (-964A/G) polymorphism might enhance cancer risk in Chinese people (Xu et al., 2014). On the other hand, another study did not find any impact for IL-27p28 SNPs on the susceptibility to colorectal cancer (Huang, Wang et al., 2012). The effect of IL-27p28 (-964A/G) on the progression of HBV infection to HCC in Chinese population was examined.No association was found between the presence of this SNP and HCC risk (Peng et al., 2013). Moreover, Yasser et al. did not find any correlation between the presence of this SNP and HBV infection among Egyptian patients (Yasser et al., 2014).

SNPs have been proposed as the next generation biomarkers for the identification of gene loci associated with various diseases and their complications (Kruglyak 1997; Schafer and Hawkins 1998). Indeed, recent studies revealed the effect of SNPs in IL-27 promoter region on modulating the progression of infectious diseases and the patient's susceptibility to therapeutic response. The effect of IL-27p28 (-964 A/G) on the progression of HBV was examined. The results showed that GG genotype is only present in the patient group of SVR and absent in the groups of relapsers and non-responders (Zicca et al., 2014). Our results showed that the presence of GG genotype only in the $\mathrm{HCV}$ infected patients may suggest a role in spontaneous resolution of HCV infection. Therefore, we propose IL-27p28 (-964 AG) as a potential genetic biomarker that can help in predicting the HCV infection outcome.

In conclusion, IL-27p28.rs153109 (-964 A/G) can be used as a genetic biomarker for predicting the outcome of HCV infection.

\section{Acknowledgements}

The authors express their gratitude to Dr Mohamed A. Mahmoud and Mrs Howayda Ahmed from the National Liver Institute, Menofiya University for their help in collecting the samples of study, and the demographic and clinical data of patients. Also, we would like to express our gratitude to Dr Eman Fathy, Dr Maha Sobhy, Dr Zainab Zakaria, Ms Walaa Ramadan and Mr Yasser Mokhtar, Dr Nabiel Mikhail (All from Egyblood, VACSERA) for their help with sample handling, storage and data entry.

\section{References}

Baldo V, et al (2008). Epidemiology of HCV infection. Curr Pharm Des, 12, 1646-54.

Parkin DM (2000). Global cancer statistics in the year. Lancet Oncol, 2, 533-43.

Badia-Martinez D (2012).Three-dimensional visualization of forming Hepatitis C virus-like particles by electrontomography. Virol, 430, 120-6.

Chen SL, Morgan TR (2006). The natural history of hepatitis C virus (HCV) infection. Int J Med Sci, 3, 47-52.

Wahid A and Dubuisson J (2013). Virus-neutralizing antibodies to hepatitis C virus. J Viral Hepat, 20, 369-76.

Koziel MJ (2005). Cellular immune responses against hepatitis $\mathrm{C}$ virus. Clin Infect Dis, 41, 25-31.

Pflanz S (2002). IL-27, a heterodimeric cytokine composed of EBI3 and p28 protein, induces proliferation of naive CD4+ $\mathrm{T}$ cells. Immunity, 16, 779-90.

Sprecher C.A, et al (1998). Cloning and characterization of a novel class I cytokine receptor. Biochem Biophys Res Commun, 246, 82-90.

Morishima N, et al (2010). A pivotal role for interleukin-27 in CD8+ T cell functions and generation of cytotoxic $\mathrm{T}$ lymphocytes. J Biomed Biotechnol, 2010, 605483.

Pflanz S (2004). WSX-1 and glycoprotein 130 constitute a signaltransducing receptor for IL-27. J Immunol, 172, 2225-31.

Kastelein RA, Hunter CA, Cua DJ (2007). Discovery and biology of IL-23 and IL-27: related but functionally distinct regulators of inflammation. Annu Rev Immunol, 25, 221-42.

Ihle J.N (2001). The Stat family in cytokine signaling. Curr Opin Cell Biol, 13, 211-7.

Takeda A (2003). Cutting edge: role of IL-27/WSX-1 signaling 
for induction of T-bet through activation of STAT1 during initial Th1 commitment. J Immunol, 170, 4886-90.

Sonobe Y (2005). Production of IL-27 and other IL-12 family cytokines by microglia and their subpopulations. Brain Res, 1040, 202-7.

Ryan E.J, Farrelly C. O' (2011). The affect of chronic hepatitis $\mathrm{C}$ infection on dendritic cell function: a summary of the experimental evidence. $J$ Viral Hepat, 18, 601-7.

Hunter CA (2005). New IL-12-family members: IL-23 and IL27, cytokines with divergent functions. Nat Rev Immunol, 5, 521-31.

Frank A.C (2010). Interleukin-27, an anti-HIV-1 cytokine, inhibits replication of hepatitis $\mathrm{C}$ virus. J Interferon Cytokine Res, 30, 427-31.

Tang T.J (2003). The role of intrahepatic immune effector cells in inflammatory liver injury and viral control during chronic hepatitis B infection. J Viral Hepat, 10, 159-67.

Imamichi T (2008). IL-27, a novel anti-HIV cytokine, activates multiple interferon-inducible genes in macrophages. AIDS, 22, 39-45.

Fakruddin J.M (2007). Noninfectious papilloma virus-like particles inhibit HIV-1 replication: implications for immune control of HIV-1 infection by IL-27. Blood, 109, 1841-9.

Liu L (2012). Influenza A virus induces interleukin-27 through cyclooxygenase-2 and protein kinase A signaling. J Biol Chem, 287, 11899-910.

Peng Q, et al (2013). Association of IL27 gene polymorphisms and HBV-related hepatocellular carcinoma risk in a Chinese population. Infect Genet Evol, 16, 1-4.

Yasser B.M, Ali a, et al (2014). Association of Interleukin 27 gene polymorphism and risk of Hepatitis B viral infection in Egyptian population. Egyptian J Medical Human Genetics, 15, 53-59.

Zicca E, et al (2014). Interleukin 27 polymorphisms in HCV RNA positive patients: is there an impact on response to interferon therapy? BMC Infect Dis, 14 ,S5.

Knapp S, et al (2011). A polymorphism in IL28B distinguishes exposed, uninfected individuals from spontaneous resolvers of HCV infection. Gastroenterol, 141, 320-5.

Abdelwahab SF (2015). Interleukin 28B.rs 12979860 genotype does not affect hepatitis $\mathrm{C}$ viral load in Egyptians with genotype 4 chronic infection. Arch Virol, 160, 2833-7.

Sharafi H (2014). The impact of IFNL4 rs 12979860 polymorphism on spontaneous clearance of hepatitis $\mathrm{C}$; a case-control study. Hepat Mon, 14, e22649.

Sun H, Pan Y, Wu R, et al (2015). CD24 Ala57Val polymorphismis associated with spontaneous viralclearance in the HCVinfected Chinese population. Liver Int, 35, 786-94.

Ohno O (1997). New hepatitis C virus (HCV) genotyping system that allows for identification of HCV genotypes $1 \mathrm{a}, 1 \mathrm{~b}, 2 \mathrm{a}$, 2b, 3a, 3b, 4, 5a, and 6a. J Clin Microbiol, 35, 201-7.

Yasser B.M.A, et al (2014). Association of Interleukin 27 gene polymorphism and risk of Hepatitis B viral infection in Egyptian population. Egyptian J Medical Human Genetics, 15, 53-59.

Batten M, Ghilardi N (2007). The biology and therapeutic potential of interleukin 27. J Mol Med (Berl), 85, 661-72.

Komatsu H, et al (2014). Association between single-nucleotide polymorphisms and early spontaneous hepatitis B virus e antigen seroconversion in children. BMC Res Notes, 7, 789.

Chae SC (2007). Identification of polymorphisms in human interleukin-27 and their association with asthma in a Korean population. J Hum Genet, 52, 355-61.

Li CS (2009). Interleukin-27 polymorphisms are associated with inflammatory bowel diseases in a Korean population. J Gastroenterol Hepatol, 24, 1692-6.

Xu X.P (2014). Genetic association between IL-27 rs153109 polymorphism and cancer risk in Chinese population: a meta-analysis. J Recept Signal Transduct Res, 1-6.

Huang ZQ (2012). Association of single nucleotide polymorphisms in IL-12 and IL-27 genes with colorectal cancer risk. Clin Biochem, 45, 54-9.

Kruglyak L (1997). The use of a genetic map of biallelic markers in linkage studies. Nat Genet, 17, 21-4.

Schafer AJ, Hawkins JR (1998). DNA variation and the future of human genetics. Nat Biotechnol, 16, 33-9. 